Article

\title{
Property Improvement of GaAs Surface by 1-Octadecanethiol Passivation
}

\author{
Lu Zhou®, Xuefeng Chu, Yaodan Chi and Xiaotian Yang *
}

Jilin Provincial Key Laboratory of Architectural Electricity \& Comprehensive Energy Saving, School of Electrical Engineering and Computer, Jilin Jianzhu University, Changchun 130118, China; zhoulu885@163.com (L.Z.); chuxuefeng@jlju.edu.cn (X.C.); chiyaodan@jlju.edu.cn (Y.C.)

* Correspondence: yangxiaotian@jlju.edu.cn; Tel.: +86-0431-84566469

Received: 21 January 2019; Accepted: 28 February 2019; Published: 5 March 2019

check for updates

\begin{abstract}
In this study the effects of 1-Octadecanethiol (ODT, 1- $\mathrm{CH}_{3}\left[\mathrm{CH}_{2}\right]_{17} \mathrm{SH}$ ) passivation on GaAs (100) surface and $\mathrm{GaAs} / \mathrm{Al}_{2} \mathrm{O}_{3}$ MOS capacitors are investigated. The results measured by $\mathrm{X}$-ray photoelectric spectroscopy (XPS), Raman spectroscopy and scan electron microscopy (SEM) show that the ODT passivation can obviously suppress the formation of As-O bonds and Ga-O bonds on the GaAs surface and produce good surface morphology at the same time, and especially provide better protection against environmental degradation for at least $24 \mathrm{~h}$. The passivation time is optimized by photoluminescence (PL), and the maximum enhancement of PL intensity was $116 \%$. Finally, electrical property of a lower leakage current was measured using the metal-oxide-semiconductor capacitor (MOSCAP) method. The results confirm the effectiveness of ODT passivation on GaAs (100) surface.
\end{abstract}

Keywords: GaAs; passivation; XPS; RAMAN; PL

\section{Introduction}

Controlling the chemical and electronic properties of the III-V semiconductor surface/interface by a passivation method is a theme that has been studied extensively in the fields of semiconductor lasers [1,2], metal-oxide-semiconductor field effect transistors [3,4], and solar batteries [5] for several decades. Among various methods, sulfur passivation, e.g., using $\mathrm{CH}_{3} \mathrm{CSNH}_{2},\left(\mathrm{NH}_{4}\right)_{2} \mathrm{~S} \cdot 9 \mathrm{H}_{2} \mathrm{O}, \mathrm{S}_{2} \mathrm{Cl}$ and $\mathrm{Na}_{2} \mathrm{~S}$ [6-8] aqueous or organic solutions, have been reported widely due to their simplicity and effectiveness. They can reduce the GaAs surface state density by removing Ga-O/As-O bonds and then saturate the dangling bonds with S-. But this sulfur passivation has the prominent drawbacks of poor environmental stability, metal contamination, and $\mathrm{H}_{2} \mathrm{~S}$ volatilization, which are averse to further applications.

In contrast, the passivation by long-chain thiols $\left(\mathrm{C}_{n} \mathrm{H}_{2 \mathrm{n}+1}-\mathrm{SH}, \mathrm{n} \geq 16\right)$ self-assembled monolayers (SAMs) [9] promises better stability in air exposure due to the thicker and denser sulfur-layer. $H$. A. Budz et al. reported that SAMs of octadecanethiol deposited on GaAs from liquid and vapor phases can inhibit the oxidation of the surface for an extended period of time [10,11]. In addition, H. A. Budz [11] and Shen Ye et al. [12] reported that SAMs of alkanethiol constructed on GaAs had a hydrophobic property. Pablo Mancheno-Posso et al. [13] reported the GaAs surface passivated by 1-eicosanethiol (ET-20 C, $\mathrm{n}=20$ ) without any reoxidation for $30 \mathrm{~min}$ air exposure. Daniel Cuypers [14] reported the GaAs surface passivated by sacrificial SAMs without Fermi level pinning in the center of the forbidden band.

In this work, we systematically investigate the impact of 1-Octadecanethiol (ODT-18 C, $\mathrm{n}=20$ ) passivation on the GaAs (100) surface through a combined of X-ray photoelectric spectroscopy (XPS, Escalab 250Xi, Thermo Fisher Scientific, Waltham, MA, USA), PL-Raman (LabRAM HR Evolution, Horiba Scientific, Paris, France) and scanning electron microscope (SEM, JSM-7610F, Japan 
Electron Optics Laboratory, Tokyo, Japan) study. Finally, the leakage current was tested using a GaAs-MOSCAP structure.

\section{Experiment}

All substrates used in this study were Si-doped n-type $\left(2.4 \times 10^{18} \mathrm{~cm}^{-3}\right)$ GaAs (100) wafers. Prior to ODT ( $98 \%$, Aladdin, Shanghai, China) passivation, samples were cleaned by sonication in acetone and ethanol for at least $5 \mathrm{~min}$ each, followed by a deionized water rinse and $\mathrm{N}_{2} \mathrm{dry}$, then immersed in 5\% hydrofluoric acid (HF, 40\%, Aladdin, Shanghai, China) for $1 \mathrm{~min}$ to decrease the native oxides. To minimize air exposure after HF etching, the wafers were promptly transferred without drying to a $5 \mathrm{~mL}$ solution of the ODT in ethanol at room temperature for $24 \mathrm{~h}$.

Next, XPS, Photoluminescence (PL), Raman and SEM measurements were used to investigate the impact of 1-Octadecanethiol passivation on the GaAs (100) surface. XPS was used to examine the bonding chemistry of the GaAs surface. XPS shown in this work was taken with monochromatic $\mathrm{Al}$ $\mathrm{K} \alpha$ radiation $(1486.6 \mathrm{eV})$ with the anode operating at a power of $150 \mathrm{~W}$, and the binding energy was corrected by the $\mathrm{C} 1 \mathrm{~s}$ peak at $284.8 \mathrm{eV}$. PL-Raman spectra were recorded at room temperature using $532 \mathrm{~nm}$ laser excitation, and the acquisition time was set at $2 \mathrm{~s}$. In order to establish reproducibility between measurements, a uniform untreated GaAs sample was used as a reference. We made sure that the deviation of the reference PL intensity in all measurements was kept within $10 \%$. The electrical properties were evaluated by fabricating metal-oxide-semiconductor-capacitor (MOSCAP) with an $\mathrm{Al}(50 \mathrm{~nm})$ electrode and $\mathrm{Al}_{2} \mathrm{O}_{3}(10 \mathrm{~nm})$ insulator. All the parameters of the MOSCAP were identical except for the passivation. Here, the $\mathrm{Al}_{2} \mathrm{O}_{3}$ was prepared by atomic layer deposition (ALD) technology. Trimethyl Aluminum (TMA) and $\mathrm{H}_{2} \mathrm{O}$ were used as precursors for the ALD of $\mathrm{Al}_{2} \mathrm{O}_{3}$ layer at $150{ }^{\circ} \mathrm{C}$. Leakage current—voltage characteristics were assessed using a B1500A semiconductor device analyzer.

\section{Discussion}

The effect of ODT passivation on the bonding chemistry of GaAs was examined by collecting As $3 d$ and Ga $2 p$ spectra. Figure 1a shows the As 3d XPS spectra of the unpassivated and ODT passivated samples. It is clear that the As $3 \mathrm{~d}$ spectra of the unpassivated sample overlapped with three fitted subpeaks: $40.87 \mathrm{eV}, 41.56 \mathrm{eV}$ and $44.37 \mathrm{eV}$, respectively. The peaks at $40.87 \mathrm{eV}$ and $41.56 \mathrm{eV}$ corresponded to the As $3 \mathrm{~d} 5$ bond and As $3 \mathrm{~d} 3$ bond in GaAs bulk, while the peak at $44.37 \mathrm{eV}$ corresponded to $\mathrm{As}_{2} \mathrm{O}_{3}$, which was obvious after HF immersion. After ODT passivation, we observed an absolute removal of the $\mathrm{As}_{2} \mathrm{O}_{3}$ bond and an additional formation of an As-S (42.24 eV) bond. Inset of Figure 1a represents the $S 2 p$ spectrum, which also indicates an evident sulfur layer on the GaAs wafer.
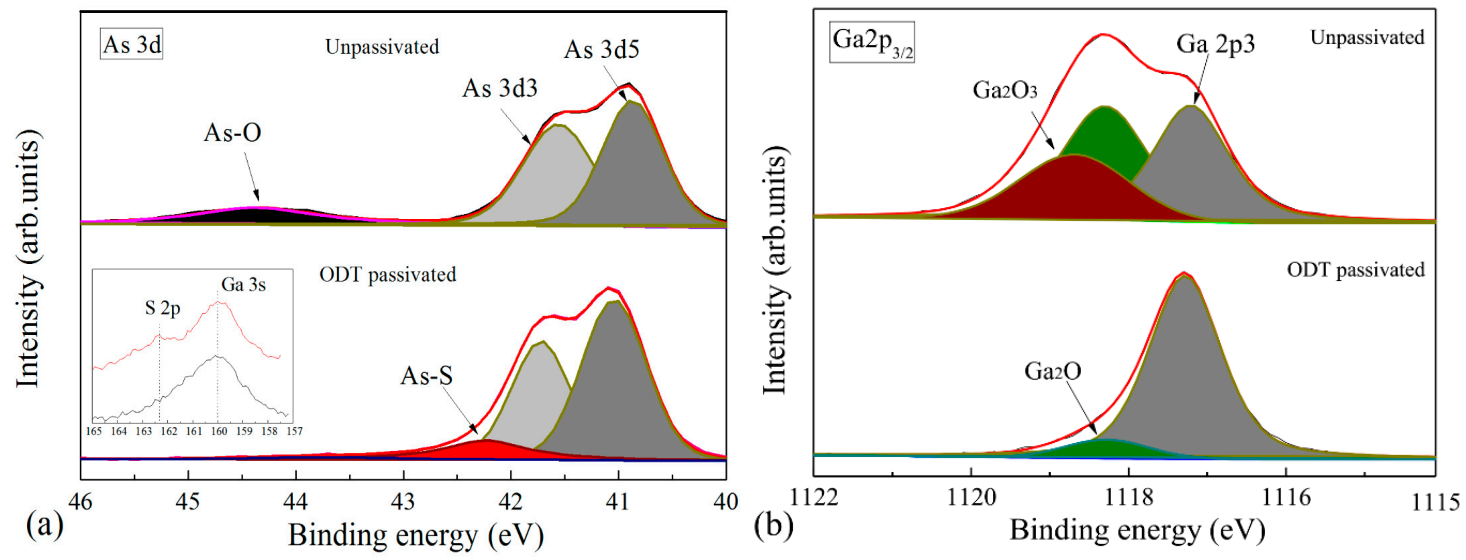

Figure 1. (a) As 3d (b) Ga 2p3/2 XPS spectra of unpassivated and ODT treated GaAs surface.

Ga $2 p$ spectra is extremely surface sensitive. In the case of the Ga $2 p_{3 / 2}$ XPS spectra, shown in Figure 1b, three distinctive subpeaks were identified: Ga-As (1117.15 eV), Ga $2 \mathrm{O}(1118.25 \mathrm{eV}), \mathrm{Ga}_{2} \mathrm{O}_{3}$ 
(1118.64 eV). After ODT passivation, the $\mathrm{Ga}_{2} \mathrm{O}_{3}$ peak was removed and the $\mathrm{Ga}_{2} \mathrm{O}$ peak dramatically decreased. Different from the formulation of the As-S bond, the examination of the Ga-S bond was difficult because of the similar binding energy between the Ga-S bond and Ga-O bond. This is consistent with the report by Pablo Mancheno-Posso [13]. The XPS comparison confirms the effectiveness of the ODT passivation for the removal of the As oxides and most Ga oxides.

In order to further demonstrate the effect of ODT passivation, especially the stability of air exposure, we prepared three groups of samples for Raman spectral analysis: unpassivated, ODT passivated and exposure in air for 3 days after ODT passivation respectively, as shown in Figure 2a-c. The longitudinal-optic-phonon-plasmon coupled (LOPC) mode near $265 \mathrm{~cm}^{-1}$ is from GaAs body material, and the longitudinal optic (LO) mode at $288 \mathrm{~cm}^{-1}$ is from the surface depletion layer. When there is a high state density on the GaAs surface, the LO mode will be measured. When the excited light penetrates deeper than the thickness of the depletion layer, LOPC mode will be measured. Therefore, an effective passivation can cause a decrease in the LO peak intensity and an increase of the LOPC peak intensity [15-17].

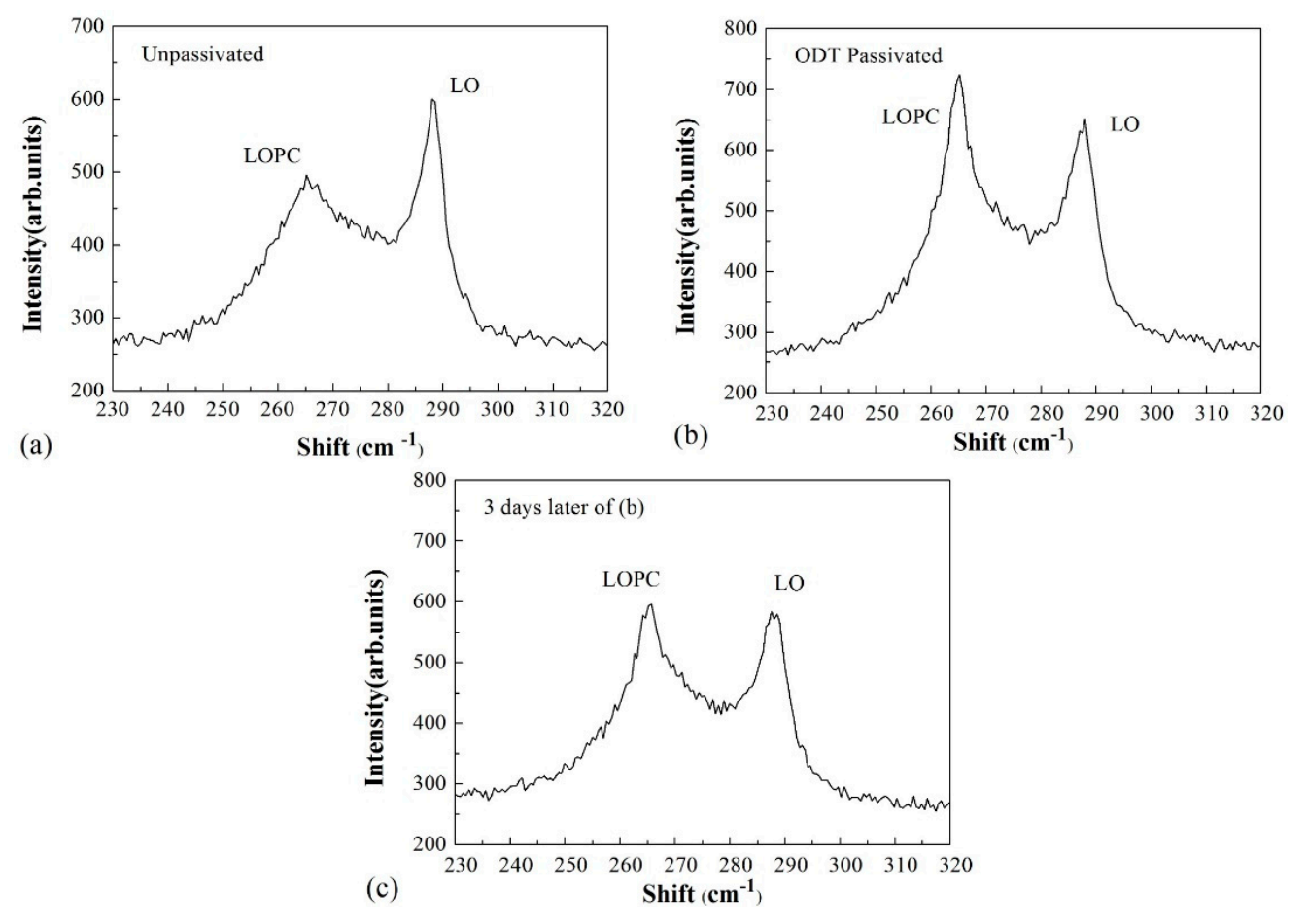

Figure 2. Raman spectra of GaAs (100) surface (a) unpassivated, (b) ODT passivated, (c) exposure in air for 3 days after ODT passivated.

It can be seen from Figure 2 that the passivation changed the balance between the LOPC $\left(265 \mathrm{~cm}^{-1}\right)$ peak and the LO $\left(288 \mathrm{~cm}^{-1}\right)$ peak. For the unpassivated GaAs surface in Figure $2 \mathrm{a}$, the ratio of peak intensity $\mathrm{I}_{\mathrm{LOPC}} / \mathrm{I}_{\mathrm{LO}}$ is 0.826 , which means the original surface state density was relatively high. After ODT passivation for $24 \mathrm{~h}$ at room temperature, the intensity of LOPC peak increased considerably indicating that the surface state density was significantly reduced, and the ratio of peak intensity $\mathrm{I}_{\mathrm{LOPC}} / \mathrm{I}_{\mathrm{LO}}$ is 1.110 in Figure $2 \mathrm{~b}$.

Figure $2 \mathrm{c}$ shows the Raman spectra of the sample placed in the air for 3 days after being passivated by ODT. It was clear that the LOPC peak was only slightly reduced compared with Figure $2 b$, we also found that the degradation rate of ODT passivation in the $\mathrm{N}_{2}$ atmosphere was nearly zero in $24 \mathrm{~h}$ (data not shown). Thus, ODT SAMs provide a good surface protection that may allow the integration of such process into GaAs semiconductor device manufacture

The GaAs surface covered with native oxide layer is the origin of the high surface state density, pinning the surface Fermi level within the band gap of semiconductor. So, the radiative transition 
is weak when the surface state density is high. The PL intensity which indicates a radiative transition band-to-band will increase when there is a decrease of state density on the GaAs surface after passivation.

The immersion time has a significant influence on the passivation effect [18], thus PL spectra was recorded at room temperature for $4 \mathrm{~h}, 8 \mathrm{~h}, 16 \mathrm{~h}, 24 \mathrm{~h}, 36 \mathrm{~h}$ and $48 \mathrm{~h}$ ODT immersion. As shown in Figure 3, the PL intensity kept a continuous enhancement as time extended in the range of $0-24 \mathrm{~h}$, which is related to the reduced oxygen contamination and the increased density of ODT molecules in the SAM. Longer ODT immersion than $24 \mathrm{~h}$ did not further improve the PL intensity obviously, and the maximum PL enhancement was $116 \%$.

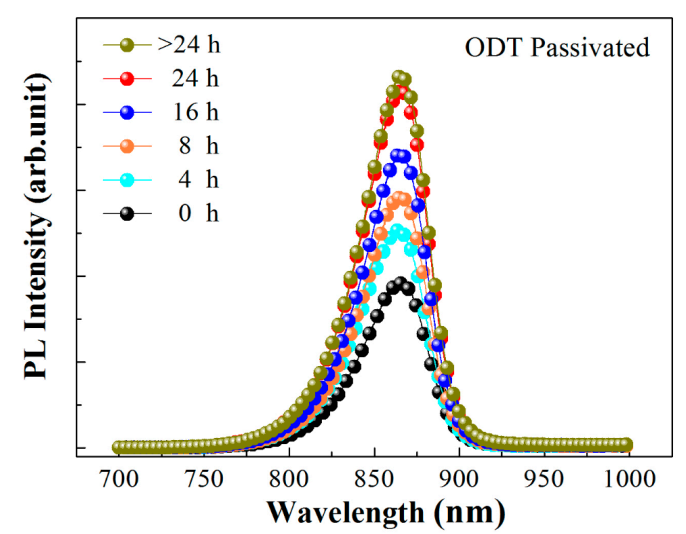

Figure 3. PL spectra of GaAs (100) surface after ODT passivation for different times.

Some surface treatment, such as plasma or acid immersion, can remove native oxides but are most likely to result in a poor surface morphology, which is harmful to subsequent device preparation. Figure 4 shows the SEM image of the GaAs (100) surface before and after ODT passivation, here the GaAs surface was pre-sprayed with Pt thin film to enhance the conductivity. It is clear that, the unpassivated surface had a poor surface morphology due to the thick native oxide layer, and a better uniform surface was achieved after ODT passivation. It is related to ODT passivation removing the native oxide and forming a regular SAMs on the surface.

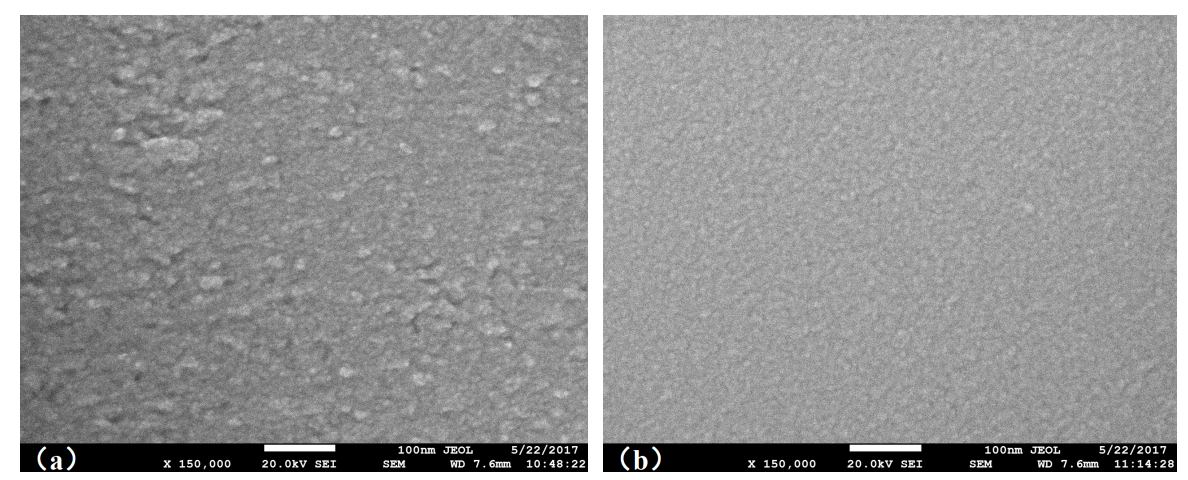

Figure 4. Contrast SEM image of GaAs surface (a) unpassivated (b) ODT passivated. The scale bar of both SEM images is $100 \mathrm{~nm}$.

Electrical measurement was performed on metal-oxide-semiconductor capacitors. Figure 5 shows the leakage current-voltage curve of $\mathrm{Al} / \mathrm{Al}_{2} \mathrm{O}_{3} / \mathrm{GaAs}-\mathrm{MOSCAP}$ before and after ODT passivation at room temperature. The $\mathrm{Al}_{2} \mathrm{O}_{3}$ was obtained by an ALD method, obtaining a final thickness of $10 \mathrm{~nm}$. It can be seen that after the ODT passivation, the device gate leakage current significantly decreased, indicating the decreased interface defects between the GaAs and the dielectric layer. 


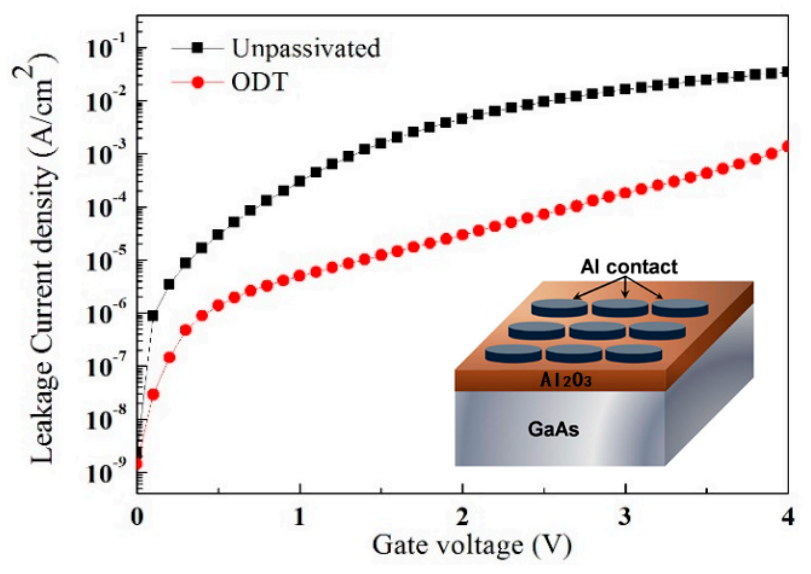

Figure 5. Leakage current density curve of $\mathrm{Al} / \mathrm{Al}_{2} \mathrm{O}_{3} / \mathrm{GaAs}-\mathrm{MOSCAP}$.

\section{Conclusions}

In summary, sulfur passivation of ODT SAMs was performed on GaAs (100) wafers. It is able to remove native oxides and shows a good surface morphology, meanwhile the ODT SAMs appears to be more stable in air exposure. PL intensity shows a continuous enhancement with passivation time, extending in the range of $0-24 \mathrm{~h}$, and the maximum PL enhancement was $116 \%$. The passivation processes uses ethanol as the only solvent and produces less sulfide volatilization, which is efficient and environmentally friendly.

Author Contributions: L.Z. designed the experiment and wrote the manuscript; X.C. performed measurements and analyzed data; Y.C. supervised and managed the project; X.Y. designed the experiment and edited the manuscript.

Funding: This work was supported by the National Natural Science Foundation of China (No. 51672103) and the Science and Technology Development Project of Jilin Province, China (No. JJKH20190865KJ, 20180623043TC and 20170520169JH).

Conflicts of Interest: The authors declare no conflict of interest.

\section{References}

1. Zhou, L.; Gao, X.; Wang, Y.; Xu, L.; Jia, B.; Bai, D.; Bo, B. Facet passivation of GaAs based LDs by plasma pretreatment and RF sputtered AlN film coating. J. Lightw. Technol. 2013, 31, 2279-2283.

2. Xu, Y.; Gao, X.; Zhang, X.; Qiao, Z.; Zhang, J.; Zhou, L.; Bo, B. Effects on the surface and luminescence properties of GaAs by SF6 plasma passivation. Crystals 2018, 8, 339. [CrossRef]

3. Robertson, J.; Guo, Y.; Lin, L. Defect state passivation at III-V oxide interfaces for complementary metal-oxide-semiconductor devices. J. Appl. Phys. 2015, 117, 112806. [CrossRef]

4. Hinkle, C.L.; Milojevic, M.; Brennan, B.; Sonnet, A.M.; Aguirre-Tostado, F.S.; Hughes, G.J.; Vogel, E.M.; Wallace, R.M. Detection of Ga suboxides and their impact on III-V passivation and fermi-level pinning. Appl. Phys. Lett. 2009, 94, 162101. [CrossRef]

5. Tajik, N.; Peng, Z.; Kuyanov, P.; LaPierre, R.R. Sulfur passivation and contact methods for GaAs nanowire solar cells. Nanotechnology 2011, 22, 225402. [CrossRef] [PubMed]

6. Lebedev, M.V.; Kunitsyna, E.V.; Calvet, W.; Mayer, T.; Jaegermann, W. Sulfur passivation of GaSb (100) surfaces: Comparison of aqueous and alcoholic sulfide solutions using synchrotron radiation photoemission spectroscopy. J. Phys. Chem. 2013, 117, 15996-16004. [CrossRef]

7. Ghita, R.V.; Negrila, C.C.; Cotirlan, C.; Logofatu, C. On the passivation of GaAs surface by sulfide compounds. Dig. J Nanomater. Biostruct. 2013, 8, 10.

8. $\quad$ Lucero, A.T.; Byun, Y.-C.; Qin, X.; Cheng, L.; Kim, H.; Wallace, R.M.; Kim, J. Formation of a ZnO/ZnS interface passivation layer on $\left(\mathrm{NH}_{4}\right)_{2} \mathrm{~S}$ treated $\mathrm{In}_{0.53} \mathrm{Ga}_{0.47} \mathrm{As}$ : Electrical and in-situ X-ray photoelectron spectroscopy characterization. Jpn. J. Appl. Phys. 2016, 55, 08PC02. [CrossRef]

9. Contreras, Y.; Mancheno-Posso, P.; Muscat, A.J. Comparison of the chemical passivation of GaAs, $\mathrm{In}_{0.53} \mathrm{Ga}_{0.47} \mathrm{As}$, and insb with 1-eicosanethiol. Sol. State Phenom. 2016, 255, 55-60. [CrossRef] 
10. Budz, H.A.; LaPierre, R.R. Properties of octadecanethiol self-assembled monolayers deposited on GaAs from liquid and vapor phases. J. Vac. Sci. Technol. Vac. Surf. Films 2008, 26, 1425-1431. [CrossRef]

11. Budz, H.A.; Biesinger, M.C.; LaPierre, R.R. Passivation of GaAs by octadecanethiol self-assembled monolayers deposited from liquid and vapor phases. J. Vac. Sci. Technol. Microelectron. Nanometer Struct. 2009, 27, 637. [CrossRef]

12. Ye, S.; Li, G.; Noda, H.; Uosaki, K.; Osawa, M. Characterization of self-assembled monolayers of alkanethiol on GaAs surface by contact angle and angle-resolved XPS measurements. Surf. Sci. 2003, 529, 163-170. [CrossRef]

13. Mancheno-Posso, P.; Muscat, A.J. Self-assembly of alkanethiolates directs sulfur bonding with GaAs (100). Appl. Surf. Sci. 2017, 397, 1-12. [CrossRef]

14. Cuypers, D.; Fleischmann, C.; Van Dorp, D.H.; Brizzi, S.; Tallarida, M.; Müller, M.; Hönicke, P.; Billen, A.; Chintala, R.; Conard, T.; et al. Sacrificial self-assembled monolayers for the passivation of GaAs (100) surfaces and interfaces. Chem. Mater. 2016, 28, 5689-5701. [CrossRef]

15. Vasily, N.; Bessolov, M.V.L.; Ivankov, A.F.; Bauhofer, W.; Dietrich, R.T.Z. Electronic properties of GaAs (100) surface passivated in alcoholic sulfide solutions. Appl. Surf. Sci. 1993, 133, 17-24.

16. Dorsten, J.F.; Maslar, J.E.; Bohn, P.W. Near-surface electronic structure in GaAs (100) modified with self-assembled monolayers of octadecylthiol. Appl. Phys. Lett. 1995, 66, 1755-1757. [CrossRef]

17. Wang, J.; Liu, X.H.; Li, Z.S.; Su, R.Z.; Ling, Z.; Cai, W.Z.; Hou, X.Y.; Wang, X. Raman scattering characterization of the crystalline qualities of ZnSe films grown on S-passivated GaAs (100) substrates. Appl. Phys. Lett. 1995, 67, 2043-2045. [CrossRef]

18. Ting Hou, C.M.G.; Keller, S.W.; Nelen, L.; Kauffman, J.F. Passivation of GaAs (100) with an adhesion promoting self-assembled monolayer. Chem. Mater. 1997, 9, 3181-3186.

(C) 2019 by the authors. Licensee MDPI, Basel, Switzerland. This article is an open access article distributed under the terms and conditions of the Creative Commons Attribution (CC BY) license (http:/ / creativecommons.org/licenses/by/4.0/). 